\title{
Leptin independently predicts development of sepsis and its outcome
}

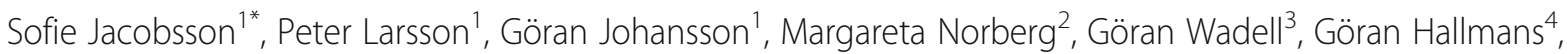 \\ Ola Winsö ${ }^{1}$ and Stefan Söderberg ${ }^{5}$
}

\begin{abstract}
Background: Sepsis is a life-threatening condition and obesity is related to the clinical outcome. The underlying reasons are incompletely understood, but the adipocyte derived hormones leptin and adiponectin may be involved.

Methods: Patients aged 18 years or more with documented first time sepsis events were included in a nested case-referent study if they had participated in previous health surveys. Two matched referents free of known sepsis were identified. Circulating levels of leptin and adiponectin were determined in stored plasma, and their impact on a future sepsis event and its outcome was evaluated.

Results: We identified 152 patients (62\% women) with a sepsis event and a previous participation in a health survey. Eighty-three \% had also blood samples from the acute event. Hyperleptinemia at health survey associated with a future sepsis event (OR 1.77, 95\% Cl 1.04-3.00) and with hospital death. After adjustment for BMI leptin remained associated with sepsis in men, but not in women. High levels in the acute phase associated with increased risk for in hospital death in women (OR 4.18,95\% Cl 1.17-15.00), while being protective in men (OR 0.05, $95 \% \mathrm{Cl} 0.01-0.48)$. Furthermore, leptin increased more from baseline to the acute phase in men than in women. Adiponectin did not predict sepsis and did not relate to outcome.

Conclusions: Hyperleptinemia independently predicted the development of sepsis and an unfavourable outcome in men, and inertia in the acute response related to worse outcome.
\end{abstract}

Keywords: Sepsis, Leptin, Adiponectin, Obesity, Case-referent study, Sex

\section{Background}

Sepsis is a life threatening condition with an increasing incidence globally [1]. In parallel, the prevalence of obesity is increasing, and obesity is common among sepsis patients and has been associated with both worse and favourable outcomes [2-4]. The underlying reasons are incompletely understood, but the adipose tissue may be an important modulator of inflammation and immunity via production of vasoactive substances such as cytokines and other peptides collectively known as adipokines $[5,6]$.

The adipokines leptin and adiponectin are involved in the inflammatory process, and they may modulate key

\footnotetext{
* Correspondence: sofie.jacobson@umu.se

${ }^{1}$ Department of Surgical and Perioperative Sciences, Anesthesiology and

Intensive Care Medicine, Umeå University Hospital, Umeå University, S-901 85

Umeå, Sweden

Full list of author information is available at the end of the article
}

processes during sepsis development such as cytokine production, immune cell proliferation and endothelial function through interaction with other cytokines and their receptors [7-10].

However, there are conflicting results regarding these adipokines and the outcome from sepsis [11-21]. Although adipokines have been associated with the prognosis of sepsis, it is not clear if adipokines promotes an infectious process to become septic or are related to the outcome of the septic event [22].

In this study, we aimed to assess the risk for sepsis and its outcome related to circulating levels of adipokines both at baseline and at the acute phase. Furthermore, if these associations differed between sexes. 


\section{Methods}

Between 1 March 1988 and 31 October 2008, a total of 797 patients were admitted with a diagnosis of sepsis at the Intensive Care Unit, Umeå University Hospital, Sweden. The diagnosis of sepsis and the severity of sepsis were confirmed retrospectively by reviewing hospital records, including results from biochemical, microbiological, and radiological examinations.

Prior to the septic event, 152 of the 797 had participated in one of four population-based health studies in Northern Sweden: the Västerbotten Intervention Program (VIP), the Northern Sweden MONItoring Of trends and Determinants in CArdivascular Disease (MONICA) survey, the Mammary Screening Program (MSP), and the Northern Sweden Maternity Cohort (NSMC). The contribution of cases from each survey was 81 (VIP), 4 (MONICA), 43 (MSP), and 24 (NSMC).

$\mathrm{VIP}$ is an ongoing community intervention program targeting cardiovascular disease and diabetes prevention [23]. Subjects are asked to participate in a health survey at their primary health centre at the ages of $30,40,50$ and 60 years. However, those aged 30 are no longer invited because of a lack of resources. The participation rate was initially $55 \%$ but has increased and is now approximately $65 \%$. The total number of unique individuals surveyed in VIP was 85,600 as of 31 December 2009.

MONICA consists of randomly selected individuals aged 25-74 years from the counties of Norr- and Västerbotten, who were invited to participate in a health study. The study has been repeated six times until 2009 and 10,300 unique persons participated (74\% of those invited) [24].

Data for the MSP cohort, consisting of 28,700 women, were collected between 1995 and 2006 when the women attended their regular mammography exam and were asked to donate blood samples for research. In addition, anthropometric measurements were taken.

In VIP, MONICA and MSP, participants were asked to donate blood to the Northern Sweden Biobank for future research, and blood was stored at $-80{ }^{\circ} \mathrm{C}$ until further analysis. Participants were fasting before sampling for a minimum of $4 \mathrm{~h}$ (extended to $8 \mathrm{~h}$ in 1992).

The Northern Sweden Maternity Cohort (NSMC) consists of all women in the study area who were screened for rubella immunity during pregnancy, and the total number of participants were 91,000 as of 31 December 2009. Remaining samples from rubella screening as well as from routine clinical serological and viral analyses have been stored at $-20^{\circ} \mathrm{C}$ since 1975 at the Department of Virology, Umeå University.

For each septic case, two referents from the same cohort without any episode of sepsis and being alive at the date of the case admission to ICU were chosen and matched for age ( \pm 2 years), gender, and time of blood sampling ( \pm 30 days). Matching on smoking $(y / n)$ was incomplete due to missing information, mainly in the MSP.

In addition, 128 out of 152 patients had also retrievable samples collected at ICU admission (the acute phase).

The study protocol was approved by the Regional Ethical Review Board in Umeå and by the Swedish National Computer Data Inspection Board, and complies with the Declaration of Helsinki. All participants gave written informed consent for future use of data and blood samples.

\section{The septic event (acute phase)}

Patients aged 18 years or older with a diagnosis of sepsis within $24 \mathrm{~h}$ after admittance to the intensive care unit (ICU) were included.

For patients with multiple admissions due to sepsis, only the first event was included. Sepsis, severe sepsis or septic shock was defined according to standard definitions [25]. Acute Physiology, Age and Chronic Health Evaluation (APACHE) II score was calculated and used for assessment of severity of illness at admission [26]. Sequential Organ Failure Assessment Score (SOFA) as a marker for organ dysfunction and disease severity was calculated at admission [27]. Data on height and weight were recorded, if present, and body mass index (BMI) was calculated as weight $(\mathrm{kg})$ divided by height $(\mathrm{m})$ squared. Data on length of stay, mortality, referral patterns, and reasons for admission, co-morbidities, and sources of infection, primary infection sites and causative microorganisms were collected. Microbiological cultures were considered relevant if acquired within $48 \mathrm{~h}$ before or after admission to the ICU. Pre-existing diseases were defined according to Knaus et al. [26].

\section{Clinical examinations at baseline (health survey)}

In VIP and MONICA, participants were asked to complete a health questionnaire about their living conditions and cardiovascular risk factors, and anthropometry and blood pressure were measured. An oral glucose tolerance test with measurements of fasting and post-load glucose levels was routinely performed in VIP and in $60 \%$ of the MONICA participants but was not obtained in MSP and in NSMC. Diabetes and intermediate forms of glucose intolerance were determined according to WHO guidelines [28].

In the MONICA and MSP surveys, blood pressure was recorded in the sitting position after $5 \mathrm{~min}$ of rest, initially using a mercury sphygmomanometer but since 2004 by using semi-automatic devices (Omron M7, Omron Corp., Kyoto, Japan). In the VIP survey, blood pressure was measured after 5 min of rest in the recumbent position until 1 September 2009 and thereafter in 
the sitting position using devices as above. The measurements obtained in the recumbent position were adjusted according to a sex- and age-specific formula [29]. Hypertension was defined as systolic BP $\geq 140 \mathrm{mmHg}$ and/or diastolic $\mathrm{BP} \geq 90 \mathrm{mmHg}$ and/or on anti-hypertensive medication.

Weight was measured without shoes in light indoor clothing and recorded to the nearest $0.2 \mathrm{~kg}$. Height was measured to the nearest centimetre, without shoes, and BMI was calculated.

Subjects were categorized as daily smokers, ex-smokers or non-smokers. Total serum cholesterol was measured using a bench-top analyser (Reflotron ${ }^{\mathrm{R}}$, Boehringer Mannheim GmbH Diagnostica, Mannheim, Germany) at the time of the health survey (VIP, until 1 September 2009) or by an enzymatic method (Boehringer Mannheim $\mathrm{GmbH}$ Diagnostica, Mannheim, Germany) at a central laboratory (MONICA and VIP after 1 September 2009). Cholesterol values obtained using the bench-top method were adjusted to the results measured at the central laboratory.

No clinical examinations were performed in the NSMC.

\section{Chemical analyses}

Leptin and adiponectin were analysed in stored plasma obtained at the baseline health survey with a doubleantibody radioimmunoassay method (Millipore Corporation, Billerica, MA, USA). The detectable level of the assays is $0.5 \mathrm{ng} / \mathrm{mL}$. The total coefficient of variation (CV) for leptin was $4.7 \%$ at both low $(2-4 \mathrm{ng} / \mathrm{mL})$ and high $(10-15 \mathrm{ng} / \mathrm{mL})$ levels. For adiponectin, the total CV was $15.2 \%$ at low levels $(2-4 \mu \mathrm{g} / \mathrm{mL})$ and $8.8 \%$ at high $(26-54 \mu \mathrm{g} / \mathrm{mL})$ levels.

\section{Statistical analyses}

Data are presented as numerical values or percentages. Non-normally distributed data were $\log _{\mathrm{e}}$-transformed prior to analysis. Continuous data are presented as (geometric) means with 95\% confidence intervals (CI). Pearson correlation or Spearman's rho was used for test of associations. For comparisons, Fisher's exact, Student t, or Mann-Whitney U-tests were used when appropriate. Paired sample ttest was used for intra-individual comparison. Since cases and referents had the same follow-up time within strata in this nested and matched case-referent study, logistic regression analysis (rather than Cox regression) using the conditional maximum likelihood routine designed for matched analysis was uses to estimate odds ratios (OR) and 95\% CIs, and the influence of studied variables on future sepsis (stratified sex) was tested in univariable and multivariable models. Missing continuous values (BMI and serum cholesterol) were replaced with the cohort- and sex-specific median values representing the referents and missing values for categorical variables were treated as a separate category (not shown in tables). Non-conditional logistic regression analysis was used to calculate the risk for in-hospital death. Leptin and adiponectin were tested both as continuous ( $\log _{\mathrm{e}}$-transformed) and categorical (quartiles) variables. Cut-offs for quartiles were based on the cohort and sexspecific distribution of the baseline adipokine levels amongst referents (risk for sepsis) or amongst cases (risk for death). A $p$-value $<0.05$ was considered significant, and all $p$-values reported are two-sided. No adjustment was made for multiple testing. SPSS ver. 22 was used for statistical analysis.

\section{Results}

\section{Subject characteristics}

Subject with future sepsis had marginally higher BMI and lower total cholesterol than matched referents (Table 1). Prevalences of diabetes and hypertension, fasting and post-load blood glucose levels did not differ between cases and their referents. Circulating levels of leptin and adiponectin did not differ between cases and their referents. As expected, women had higher leptin $(P<0.001)$ and adiponectin $(P<0.001)$ levels (Figs. 1 and 2, respectively).

The acute event was classified as sepsis in $26 \%$, as severe sepsis in $52 \%$ and as septic shock in $22 \%$, with no differences between men and women (Table 2). The ICU mortality was $18 \%$ and the hospital mortality was $21 \%$. The median time between survey participation and event was 6.5 years (IQR 7.7). The mean age at sepsis onset was 56.1 years in women and 61.0. years in men.The frequency of co-morbidities, including diabetes, steroid treatment, and renal insufficiency at the time of the sepsis event was similar in men and women (Table 2).

\section{Correlations}

At baseline, BMI correlated with high circulating levels of leptin $(r=0.36, P<0.001)$, and with low circulating levels of adiponectin $(r=-0.24, P<0.001)$. In contrast, BMI did not associate with leptin $(r=-0.05, P=0.60)$ or with adiponectin $(\mathrm{r}=-0.05, P=0.44)$ in the acute phase. Furthermore, leptin and adiponectin levels in the acute phase did not correlate with severity of disease expressed as APACHE- (leptin; $P=0.95$, adiponectin; $P=0.79$ ) or SOFA- scores (leptin; $P=0.88$, adiponectin; $P=0.94)$. Leptin and adiponectin did not correlate at baseline $(P=0.14)$ or in the acute phase $(P=0.92)$.

\section{Predictors of sepsis at baseline}

High circulating levels of leptin predicted a first-ever sepsis event (OR 2.04, 95\% CI 1.30-3.2, $P=0.002)$ and retained predictive value after adjustment for BMI (OR $1.89,95 \% \mathrm{CI} 1.14-3.13, P=0.01)$ and in the fully adjusted model (OR 1.77, 95\% CI 1.04-3.00, $P=0.03$ ) (Fig. 2). None of the included confounders remained significantly associated with sepsis in the fully adjusted model (data 
Table 1 Subject characteristics at baseline survey

\begin{tabular}{|c|c|c|c|c|c|c|}
\hline & $\mathrm{n}=$ cases $/$ referents & Cases & $95 \% \mathrm{Cl}$ & Referents & $95 \% \mathrm{Cl}$ & $p$ \\
\hline Age years & $152 / 304$ & 50.9 & $48.8-53.0$ & 50.9 & $49.4-52.4$ & Matched \\
\hline Female gender, $\%$ & $152 / 304$ & 62.5 & $54.6-69.8$ & 62.5 & $56.9-67.8$ & Matched \\
\hline $\mathrm{BMl}, \mathrm{kg} / \mathrm{m}^{2}$ & $118 / 233$ & 27.1 & $26.2-28.1$ & 26.1 & $25.6-26.6$ & 0.05 \\
\hline Fasting glucose, mmol/L & $82 / 157$ & 5.5 & $5.2-5.8$ & 5.4 & $5.3-5.6$ & 0.41 \\
\hline Postload glucose, mmol/L & $74 / 148$ & 6.9 & $6.4-7.4$ & 6.4 & $6.1-6.7$ & 0.09 \\
\hline Reduced glucose tolerance, \% & $81 / 153$ & 35.8 & $25.1-46.5$ & 24.2 & $17.3-31.0$ & 0.07 \\
\hline Daily smoker, \% \# & $116 / 232$ & 33.6 & $24.9-42.4$ & 31.5 & $25.4-37.5$ & Matched \\
\hline Systolic BP, mmHg & $84 / 160$ & 135 & $130-140$ & 132 & $129-135$ & 0.28 \\
\hline Diastolic BP, mmHg & $84 / 160$ & 82 & $80-85$ & 82 & $80-83$ & 0.60 \\
\hline Hypertension, \% & $84 / 160$ & 56.0 & $45.1-66.8$ & 43.1 & $35.4-50.9$ & 0.06 \\
\hline Cholesterol, mmol/La & $84 / 157$ & 5.6 & $5.4-5.8$ & 5.9 & $5.7-6.0$ & 0.05 \\
\hline HDL cholesterol, mmol/Lo & $26 / 59$ & 1.17 & $0.89-1.54$ & 1.1 & $1.00-1.2$ & 0.60 \\
\hline Triglycerides, mmol/La & $60 / 135$ & 1.4 & $1.2-1.6$ & 1.4 & $1.3-1.4$ & 0.52 \\
\hline
\end{tabular}

Values reported are means (ageometric means) or percentages (\%) with $95 \% \mathrm{Cl}$. Hypertension was defined as systolic $\mathrm{BP}>140 \mathrm{mmHg}$ and/or diastolic $\mathrm{BP}>90 \mathrm{mmHg}$ and/or antihypertensive treatment. Reduced glucose tolerance included any of IFG, OGT or DM

Abbreviations: DM diabetes mellitus, IFG impaired fasting glucose, IGT impaired glucose tolerance (see text for definitions of DM, IFG and IGT), HDL high density lipoprotein, $B P$ blood pressure

not shown). The septic event was graded as sepsis, severe sepsis or septic shock, and a graded response was seen in that there were stronger BMI-independent associations between hyperleptinemia and more severe forms of sepsis compared to milder forms of sepsis. Furthermore, leptin predicted sepsis-related in-hospital deaths (Fig. 2). Stratified for sex hyperleptinemia predicted sepsis in both men (OR 2.39, 95\% CI 1.18-4.86, $P=0.02$ ) and women (OR 1.83, $95 \%$ CI 1.02-3.27, $P=0.04)$. This association remained in men after adjustment for BMI (OR 2.60, 95\% CI 1.20-5.61, $P=0.02)$, but not in women $(P=0.36)$. Furthermore, leptin predicted independently in-hospital death in men (OR 6.41 95\% (1.32-31.1, $P=0.02$ ). Adiponectin levels were not associated with the development of sepsis in any model (data not shown).

\section{Changes in leptin and adiponectin levels between baseline and the acute phase}

Contrary to baseline, there were no differences in leptinor adiponectin levels between men and women in the acute phase (leptin; $P=0.26$, adiponectin; $P=0.36$ ), (Fig. 3). However, the increase in both leptin- and

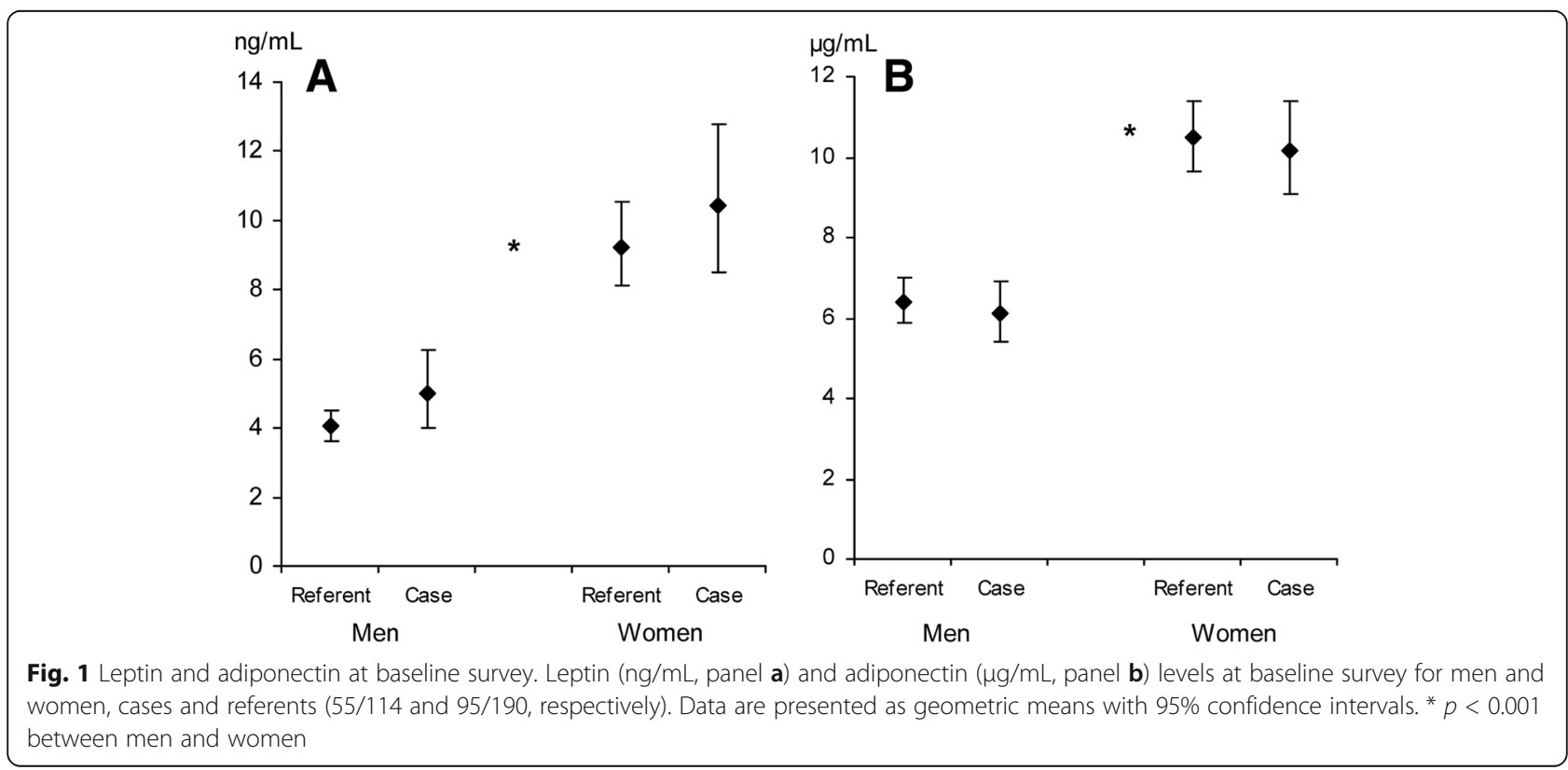




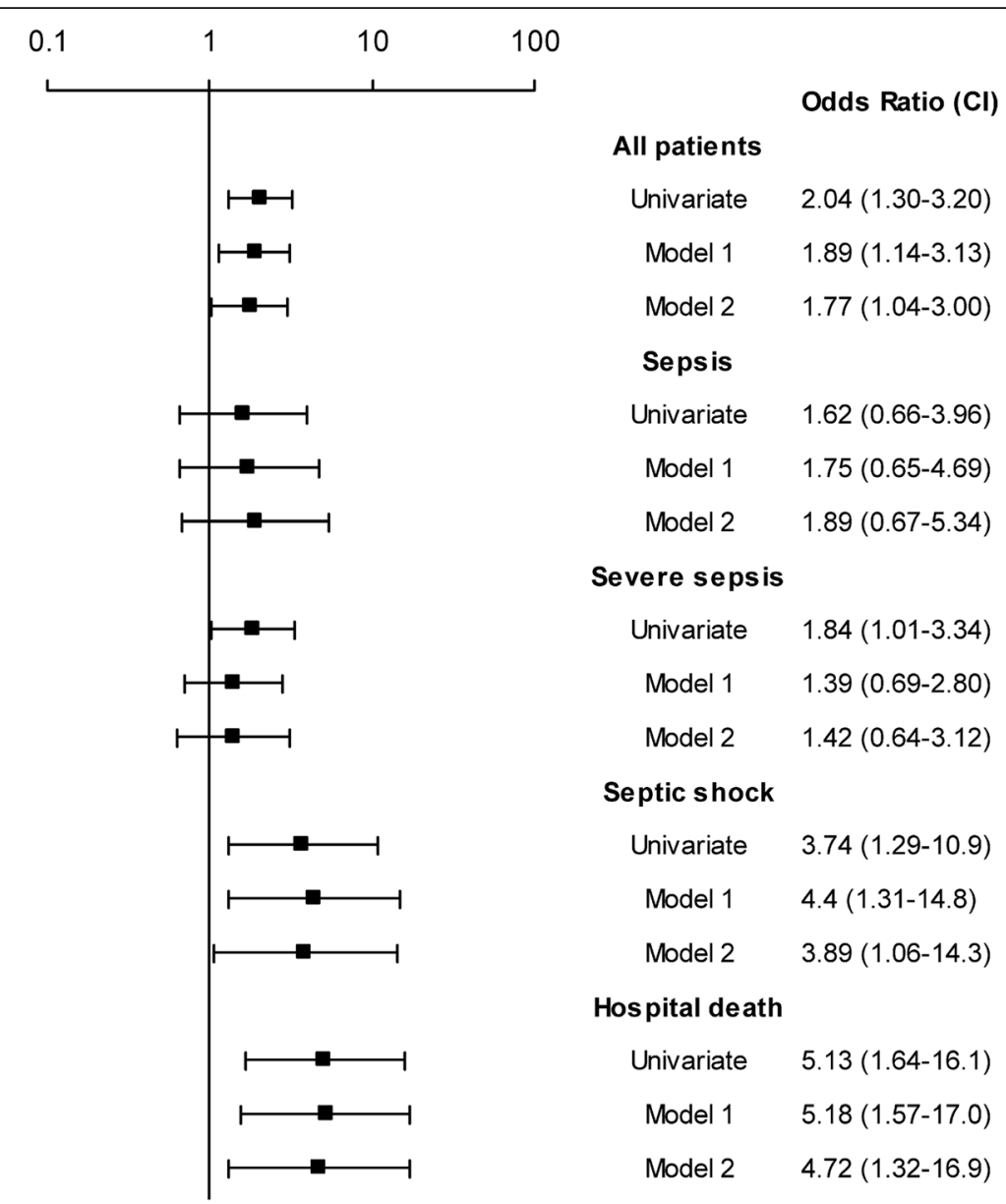

Fig. 2 Leptin a baseline survey as predictor for sepsis. Values shown are odds ratios (OR) with 95\% confidence intervals for leptin levels at baseline survey and the risk for a future sepsis event. Leptin were categorized into quartiles based on the cohort and sex-specific distribution amongst referents. The ORs represent the increased risk associated with the upper quartile of leptin (Q4) versus the reference (OR 1.00, lower three quartiles (Q1_3)). Model 1 included BMI, and model 2 included BMI, hypertension, reduced glucose tolerance (IFG, IGT a/o DM), and total cholesterol. Footnote: Cut-offs Q1_3 versus Q4 in absolute values for the different cohorts stratified for sex are for leptin ( $\mathrm{ng} / \mathrm{mL}$ ): MONICA; 6.7 (only men): VIP; men 5.3, women 19.4: MSP 22.2 and NSMC 6.0 (only women in both) and for adiponectin (mg/mL): MONICA; 14.2 (only men): VIP; men 9.3, women 10.8: MSP 13.3 and NSMC 23.5 (only women in both)Abbreviations: MONICA, the Northern Sweden MONItoring Of trends and Determinants in CArdivascular Disease; VIP,

Västerbotten Intervention Program; MSP, the Mammary Screening Program; NSMC, Northern Sweden Maternity Cohort

adiponectin levels between baseline and the acute phase were significantly higher in men than in women (leptin $P=0.001$, adiponectin $P=0.02$ ). Leptin levels increased from baseline to the acute phase in surviving men $(P=0.001)$ whereas surviving women decreased their leptin levels from baseline to the acute phase $(P=0.02)$ (Fig. 4a). There was no significant change in leptin levels from baseline to the acute phase in non-survivors (men; $P=0.09$, women; $P=0.31$ ) (Fig. 4a).

Adiponectin levels increased from baseline to the acute phase in both surviving and non-surviving men whereas surviving and non-surviving women decreased their adiponectin levels from baseline to the acute phase, however the changes were not statistically significant (Fig. 4b).

\section{Predictors of in-hospital death}

High leptin levels expressed as the highest three quartiles compared to the lowest quartile predicted death irrespective of disease severity (APACHE II or SOFA score) in women (OR 4.18, 95\% CI 1.17-15.00, $P=0.03$ ), whereas high leptin levels in men were associated with a decreased risk of death (OR 0.05, 95\% CI 0.01-0.48, $P=0.01$ ) (Fig. 5). Adjustment with SOFA score gave similar point estimates. Furthermore, leptin levels were dichotomised using a single cut-off for both men and women $(10 \mathrm{ng} / \mathrm{mL})$. Levels above $10 \mathrm{ng} / \mathrm{mL}$ were significantly associated with in hospital death, OR 2.48, 95\% (1.06-5.77, $P=0.035)$, which remained after adjustment for APACHE II; OR 2.68, 95\% CI (1.08-6.65), $P=0.033$, but not after adjustment for SOFA score, OR 2.15 95\% CI (0.86-5.39), $P=0.10$. 
Table 2 Patient characteristics at ICU admission

\begin{tabular}{|c|c|c|c|}
\hline & \multirow{2}{*}{$\begin{array}{l}\text { Men } \\
n=57\end{array}$} & \multirow{2}{*}{$\begin{array}{l}\text { Women } \\
n=95\end{array}$} & \multirow[t]{2}{*}{$p$} \\
\hline & & & \\
\hline Age years & $60.5(57.6-63.4)$ & $56.3(53.4-59.2)$ & 0.02 \\
\hline $\begin{array}{l}\text { Time between survey and } \\
\text { sepsis years (median) }\end{array}$ & 7.8 (IQR 8.3) & $6.6(\mathrm{IQR} 8.1)$ & 0.16 \\
\hline \multicolumn{4}{|l|}{ Disease scores } \\
\hline APACHE II Score & $18.2(16.3-20.1)$ & $18.9(17.4-20.3)$ & 0.57 \\
\hline SOFA score & $7.0(6.0-8.0)$ & $7.0(6.2-7.8)$ & 0.95 \\
\hline \multicolumn{4}{|l|}{ Disease severity n (\%) } \\
\hline Sepsis & $17(29.8)$ & $22(23.2)$ & 0.44 \\
\hline Severe sepsis & $32(56.1)$ & $47(49.5)$ & 0.50 \\
\hline Septic shock & $8(14.0)$ & $26(27.4)$ & 0.07 \\
\hline Hospital mortality & $13(22.8)$ & $19(20.0)$ & 0.69 \\
\hline \multicolumn{4}{|l|}{ Co-morbidities n (\%) } \\
\hline COPD & $1(1.8)$ & $3(3.2)$ & 1.00 \\
\hline Congestive heart failure & $3(5.3)$ & $2(2.1)$ & 0.36 \\
\hline Chronic renal insufficiency & $2(3.5)$ & $2(2.1)$ & 0.63 \\
\hline \multicolumn{4}{|l|}{ Diabetes n (\%) } \\
\hline Insulin treatment & $4(7.0)$ & $7(7.4)$ & 1.00 \\
\hline Other treatments & $4(7.0)$ & $5(5.3)$ & 0.73 \\
\hline \multicolumn{4}{|l|}{ Cancer n (\%) } \\
\hline Hematological & $4(7.0)$ & $5(5.3)$ & 0.73 \\
\hline Localized & $9(15.8)$ & $11(11.6)$ & 0.47 \\
\hline Metastatic & $5(8.8)$ & $6(6.3)$ & 0.75 \\
\hline \multicolumn{4}{|l|}{ Immunosuppressants n (\%) } \\
\hline Chronic steroids & $3(5.3)$ & $5(5.3)$ & 1.00 \\
\hline Chemotherapy & $7(12.3)$ & $6(6.3)$ & 0.24 \\
\hline Other immunosuppression & $4(7.0)$ & $7(7.4)$ & 1.00 \\
\hline \multicolumn{4}{|l|}{ Primary infection site $\mathrm{n}(\%)$} \\
\hline Pneumonia & $11(19)$ & $13(14)$ & 0.37 \\
\hline Abdominopelvic & $19(33)$ & $31(33)$ & 1.00 \\
\hline Urinary tract & $10(18)$ & $11(12)$ & 0.34 \\
\hline Other & $17(30)$ & $38(40)$ & 0.23 \\
\hline Unknown & $2(3.5)$ & $3(3.2)$ & 1.00 \\
\hline
\end{tabular}

Values shown are means $(95 \% \mathrm{Cl})$, medians (IQR) and numbers (\%) Abbreviations: APACHE acute physiology, age and chronic health evaluation, SOFA sequential organ failure assessment, $\mathrm{Cl}$ confidence interval, IQR interquartile range, COPD chronic obstructive pulmonary disease, ICU intensive care unit

This risk for in-hospital death remained in women, OR $7.48,95 \%$ CI $(2.30-24.28), P=0.001$, but not in men, OR $0.49,95 \%$ CI $(0.12-1.95), P=0.31$. When analyzed as a continuous $\log _{\mathrm{e}}$-transformed variable, high leptin in the acute phase predicted in-hospital death independently of APACHE II-score in women (OR 1.58, 95\% CI 1.01-2.48, $P=0.04$ ), whereas the protective effect of high leptin levels in men did not remain significant (OR 0.80, 95\% CI 0.42-1.49, $P=0.48$ ).

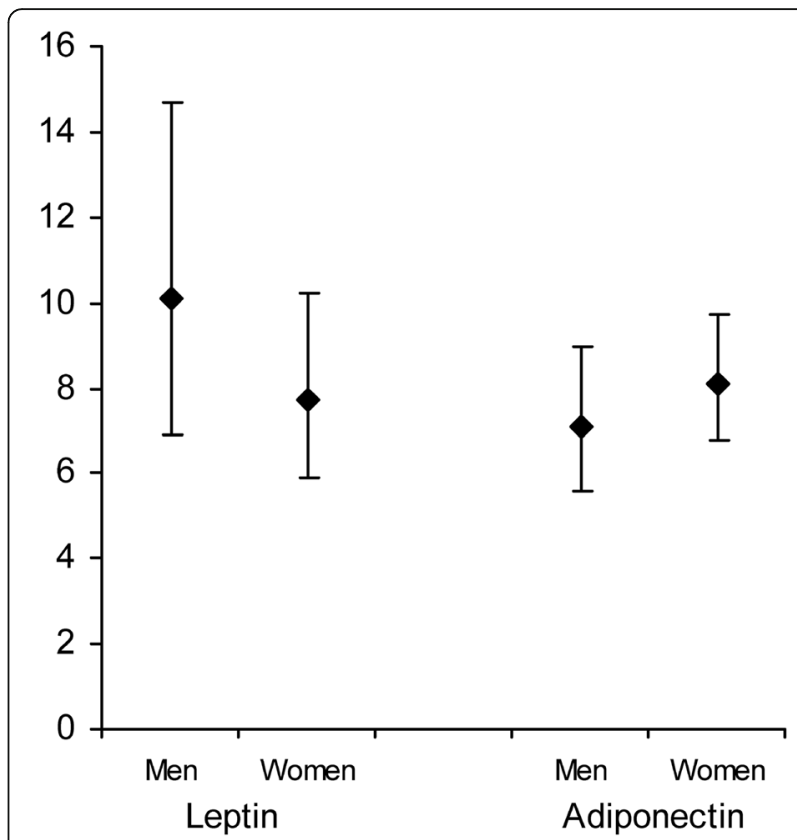

Fig. 3 Leptin- and adiponectin in the acute phase. Leptin ( $\mathrm{ng} / \mathrm{mL}$ ) and adiponectin $(\mu \mathrm{g} / \mathrm{mL})$ levels at the acute phase for men $(n=48)$ and women $(n=80)$. Data are presented as geometric means with 95\% confidence intervals

APACHE II and SOFA scores remained associated with in-hospital death after adjustment for leptin levels in the acute phase $(P<0.001$ for both APACHE and SOFA).

Adiponectin did not associate with in-hospital death, neither as a categorical variable, nor as a continuous variable (Fig. 5).

\section{Discussion}

To our knowledge, this is the first study to prospectively analyse serum levels of leptin and adiponectin in patients who subsequently develop sepsis. Furthermore, we are not aware of any previous studies of intraindividual changes in adipokine levels from a non-septic basal state to an acute septic state and the associations with outcome with a possible sex-difference.

Here we report that high levels of circulating leptin at baseline independently predicted a first-ever sepsis event, possibly with a sex-related difference. Furthermore, there was a graded response, with stronger associations between hyperleptinemia at baseline and more severe forms of sepsis compared to milder forms of sepsis. In contrast to baseline, levels of adipokines did not differ between men and women in the acute phase, primarily due to a higher increase in adipokine levels in men than in women. Furthermore, increased leptin levels in the acute phase were associated with better survival in men but not in women. 


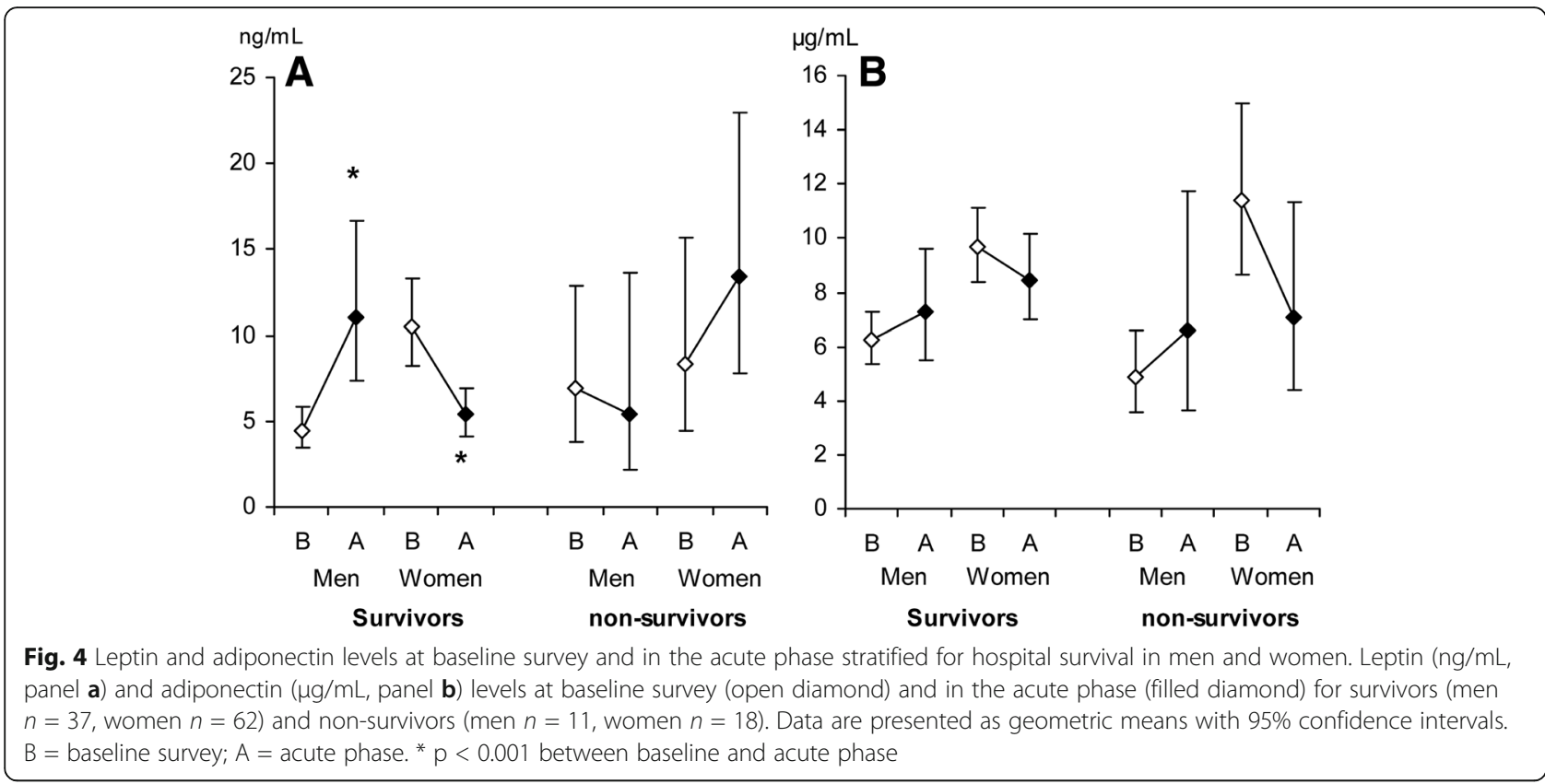

In contrast, adiponectin at baseline was not associated with the development of sepsis and adiponectin levels in the acute phase were not associated with outcome.

Our results are consistent with earlier reports showing that high leptin levels are related to better outcome in acute sepsis $[15,16,18,30]$. However, we saw this association in men.

In contrast, we found that high leptin levels at baseline predicted sepsis with an unfavourable outcome. This apparent contradiction might reflect the pleiotropic properties of adipokines. Leptin and adiponectin are adipocyte-derived cytokines with pro- and antiinflammatory effects, linking adipose tissue with metabolism and inflammation [31, 32]. Baseline leptin and adiponectin levels reflect the metabolic conditions at the time and are determined by nutritional status and correlate to the amount of fat mass, where leptin increase and adiponectin decrease with increasing obesity. These aberrations relate to the development of cardiovascular disease (CVD) and diabetes [33, 34], possibly by inducing endothelial dysfunction [35].

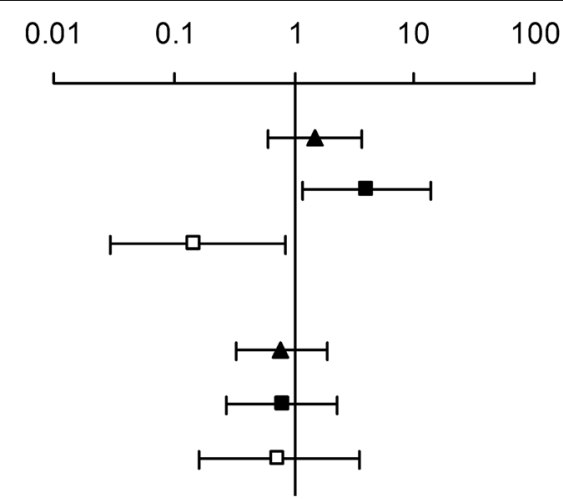

\section{Leptin \\ All patients \\ Women \\ Men}

Adiponectin

All patients

Women

Men

\section{Odds Ratio (Cl)}

$1.50(0.60-3.73)$

$3.98(1.18-13.5)$

$0.15(0.03-0.85)$

$0.78(0.33-1.85)$

$0.79(0.27-2.28)$

$0.74(0.16-3.43)$

Fig. 5 Leptin and adiponectin in acute phase as predictors for in-hospital death. Values shown are Odds ratios (OR) with 95\% confidence intervals for leptin and adiponectin concentrations in the acute phase and risk for in-hospital death for all (filled triangle, $n=128$ ), for women (filled square, $n=80$ ), and for men (open square, $n=48$ ). Leptin and adiponectin were categorized into quartiles based on the cohort and sex-specific distribution amongst cases at baseline. The ORs represent the increased risk associated with the higher three quartiles (Q2_4) versus the reference (OR 1.00, the lowest Q1). Footnote: Cut-offs Q1 versus Q2_4 in absolute values for the different cohorts stratified for sex are for leptin (ng/mL): MONICA; 5.7 (only men): VIP; men 2.6, women 6.5: MSP 8.0 and NSMC 1.7 (only women in both) and for adiponectin (mg/mL): MONICA; 5.2 (only men): VIP; men 4.1, women 6.2: MSP 7.4 and NSMC 6.8 (only women in both). Abbreviations: MONICA, the Northern Sweden MONItoring Of trends and Determinants in CArdivascular Disease; VIP, Västerbotten Intervention Program; MSP, the Mammary Screening Program; NSMC, Northern Sweden Maternity Cohort 
Hyperleptinemia also induces a low-grade pro-inflammatory state where cells in the innate immune system are activated and release cytokines. Furthermore, activation of the innate immune system induces leptin secretion. Thus, there are bidirectional loops between the inflammatory response and leptin. A key-feature in the sepsis syndrome is the acute systemic inflammation with capillary leakage and vasoplegia, which leads to severe hypotension and septic shock. It is reasonable to believe that patients with obesity-induced low grade inflammatory state with impaired endothelial function, may have an unfavourable outcome from a superimposed infection with accompanying endothelial activation and the consequent development of severe sepsis or septic shock [35-37]. However, in the acute phase, the ability to secret sufficient amounts of adipokines may be beneficial by activating the immune response.

In the acute phase, the expected association between BMI and leptin was not seen, and the difference in circulating levels between men and women was attenuated, indicating that leptin is not only a simple measure of obesity but also a complex hormone with acute-phase properties [32, 38]. The equalization of adipokine levels between sexes in the acute phase was mainly due to a greater increase in men. Equalization in leptin levels between sexes have also been reported in children with sepsis and that children with higher increases in leptin levels had an unfavourable outcome [39]. An additional increase in leptin levels from initially high levels at baseline may not be beneficial from a physiologic perspective or may indicate leptin resistance [34, 40].The differences in changes in adipokine levels in the acute septic state between men and women may in part explain conflicting results from previous studies.

We found sex-differences in the predictive value of leptin with stronger association in men. The design of this study does not allow an explanation for these gender differences, but may be due to sex-differences in leptin signalling $[41,42]$ and we have reported similar sex-related differences in leptins ability to predict stroke and diabetes [43, 44].

This study has limitations. The cases were not entirely representative of all consecutive patients admitted to the ICU as participation in a health survey prior to the sepsis event was mandatory. Two of the health surveys, the MSP and the NSMC, included only women. Further, the mean age in the NSMC was low, which explains why most our cases were (younger) women. This contrasts with most sepsis studies with a majority of men [45]. However, we believe that the matching procedure with the cases and their two referents with the same sex and within the same cohort, as well as being able to compare inter individual adipokine levels in health (baseline survey) with levels in the acute septic condition (acute phase) is a strength to this study.

The protocol for these health surveys did not include analysis of CRP, HbA1c, C-peptide or insulin and it has not been done in the present study due to limited sample volumes.

We did not exclude patients with diabetes, renal failure, patients with steroid treatment, or those with other immunosuppressive conditions; conditions that may affect adipokine levels. We thus believe that our selection represents the clinical reality. Further, the frequency of co-morbidities that could affect adipokine levels did not differ between men and women.

Although there is a strong correlation between circulating levels of adipokines and BMI, there is a significant inter-individual variation. As our prediction analysis is adjusted for BMI, the results indicate that leptin has effects independent from just being a measure of the amount of adipose tissue, an effect more pronounced in men. Despite shortcomings as a measure of fat mass, BMI still used because of its simplicity and reproducibility. The rationale for matching on smoking status was the higher risk of perioperative infectious complications related to smoking, and that smoking influence leptin levels $[46,47]$. This matching was not complete due to missing information, especially in the NSMC cohort. Repeated analysis after omitting the NSMC- or MSP cohort did not alter the results and leptin remained predictive of an event of sepsis.

Due to reduced sample size in the acute sepsis event $(n=128)$ the chosen cohort- and sex specific cut of levels for adipokines (Q1 vs Q2-4) differ from the cut of levels in the prediction analysis (Q4 vs Q1-3) (baseline samples $n=152$ ). Using cut offs of $10 \mathrm{ng} / \mathrm{mL}$ for leptin as used by others gave similar results as using cohortand sex specific Q1 vs Q2-4, with risk for in-hospital death in women and protection in men (although not significant). However, $10 \mathrm{ng} / \mathrm{ml}$ is a high leptin level in men and most patients will end up in the comparator group using this approach. As leptin physiology probably differs between men and women we argue that sexspecific cut-offs are important and the strengths of our study is the sample size which allows us to stratify the analysis for sex.

Circulating levels of leptin and adiponectin show diurnal variation and sampling at the baseline survey did not take this into account. However, if any effect this would diminish the associations found in this study. Furthermore, the samples from the pre-sepsis investigation do represent population-based levels and we have previously shown that individual leptin levels are stable over long periods of time in men and women and in different ethnicities [48]. Leptin is also stable after long-time storage of samples [49]. 


\section{Conclusion}

We conclude that hyperleptinemia at baseline predicts a first-ever sepsis event, even after adjustment for BMI and other known cardiovascular risk factors. There is a graded response between high levels of leptin at baseline and sepsis severity. In contrast, hyperleptinemia in the acute phase relates to a reduced risk for in-hospital death in men whereas hyperleptinemia relates to an increased risk in women. Furthermore, we found that inertia in the leptin response to sepsis in the acute phase was related to worse outcome, which is an intriguing finding that could be of outermost importance for the understanding of the triggers of an adequate immune response to a lifethreatening sepsis.

\section{Acknowledgements}

The authors wish to express their gratitude to the Västerbotten Intervention Project (VIP), the Northern Sweden MONICA project, the Mammary Screening Project, the Maternity Cohort of Northern Sweden, and the Medical Biobank and the funds that support these groups. We thank Åsa Ågren, Hubert Sjödin, Anna-Maja Åberg, Lennart Styrke and Eva Liedgren for expert technical assistance and Margareta Danielsson for performing the laboratory assays.

\section{Funding}

Funding that enabled collection, analysis, interpretation of data and writing the manuscript was received from the County Council of Västerbotten, Umeå University, The Swedish Medical Society, Capio, and the Kempe Foundation supported this study. SSö was supported by the Swedish Heart and Lung Foundation, and by the County Council of Västerbotten (ALF).

\section{Availability of data and materials}

All results and data are kept in the section for Anesthesiology and Intensive Care Medicine, Department of Surgical and Perioperative Science, Umeå University. These will be made available from the corresponding author on reasonable request.

\section{Conflict of interest}

No competing financial interests exist.

\section{Authors' contributions}

SS and PL designed the study, SJ extracted and evaluated patient data and performed statistical analyses. GJ contributed with statistical analyses including presentation of data in tables and figs. GH, MN and GW contributed to aspects related to the cohort design. SJ, OW and SS drafted the manuscript, and all authors revised the manuscript critically for important intellectual content. All authors approved the final version and are accountable for all aspects of the manuscript.

\section{Ethics approval and consent to participate}

The study protocol was approved by the Regional Ethical Review Board in Umeå, diary number 06-144 M, 2010-40-32 and 2011/19-32 M and by the Swedish National Computer Data Inspection Board, and complies with the Declaration of Helsinki. All participants gave written informed consent for future use of data and blood samples at the moment of the baseline survey.

\section{Consent for publication}

Data was de-identified, after collection, and therefore there was no consent required from individual patients, according to the ethical approval.

\section{Competing interests}

The authors declare that they have no competing interests.

\section{Publisher's Note}

Springer Nature remains neutral with regard to jurisdictional claims in published maps and institutional affiliations.

\section{Author details}

${ }^{1}$ Department of Surgical and Perioperative Sciences, Anesthesiology and Intensive Care Medicine, Umeå University Hospital, Umeå University, S-901 85 Umeå, Sweden. ${ }^{2}$ Department of Public Health and Clinical Medicine, Epidemiology and Global Health, Umeå University, Umeå, Sweden. ${ }^{3}$ Department of Clinical Microbiology, Umeå University, Umeå, Sweden. ${ }^{4}$ Department of Public Health and Clinical Medicine, Nutritional Research, Umeå University, Umeå, Sweden. ${ }^{5}$ Department of Public Health and Clinical Medicine, Medicine, Umeå University, Umeå, Sweden.

Received: 15 June 2017 Accepted: 4 September 2017 Published online: 11 September 2017

\section{References}

1. Dellinger RP, Levy MM, Rhodes A, Annane D, Gerlach H, Opal SM, Sevransky JE, Sprung CL, Douglas IS, Jaeschke R, et al. Surviving sepsis campaign: international guidelines for management of severe sepsis and septic shock, 2012. Intensive Care Med. 2013:39:165-228.

2. Caballero B. The global epidemic of obesity: an overview. Epidemiol Rev. 2007;29:1-5.

3. Prescott HC, Chang WW, O'Brien JM Jr, Langa KM, Iwashyna TJ. Obesity and 1-year outcomes in older Americans with severe sepsis. Crit Care Med. 2014;42:1766-74.

4. Falagas ME, Athanasoulia AP, Peppas G, Karageorgopoulos DE. Effect of body mass index on the outcome of infections: a systematic review. Obes Rev. 2009;10:280-9.

5. Vegiopoulos A, Rohm M, Herzig S. Adipose tissue: between the extremes. EMBO J. 2017;36:1999-2017.

6. Maurizi G, Della Guardia L, Maurizi A, Poloni A. Adipocytes properties and crosstalk with immune system in obesity-related inflammation. J Cell Physiol. 2017;

7. Gainsford T, Willson TA, Metcalf D, Handman E, McFarlane C, Ng A, Nicola NA, Alexander WS, Hilton DJ. Leptin can induce proliferation, differentiation, and functional activation of hemopoietic cells. Proc Natl Acad Sci U S A. 1996;93:14564-8.

8. Baumann H, Morella KK, White DW, Dembski M, Bailon PS, Kim H, Lai CF, Tartaglia LA. The full-length leptin receptor has signaling capabilities of interleukin 6-type cytokine receptors. Proc Natl Acad Sci U S A. 1996;93:8374-8.

9. Lord GM, Matarese G, Howard JK, Baker RJ, Bloom SR, Lechler RI. Leptin modulates the T-cell immune response and reverses starvation-induced immunosuppression. Nature. 1998;394:897-901.

10. Wong GW, Wang J, Hug C, Tsao TS, Lodish HF. A family of Acrp30/ adiponectin structural and functional paralogs. Proc Natl Acad Sci U S A. 2004;101:10302-7.

11. Hillenbrand A, Knippschild U, Weiss M, Schrezenmeier H, Henne-Bruns D, Huber-Lang M, Wolf AM. Sepsis induced changes of adipokines and cytokines - septic patients compared to morbidly obese patients. BMC Surg. 2010;10:26.

12. Behnes M, Brueckmann M, Lang S, Putensen C, Saur J, Borggrefe M, Hoffmann U. Alterations of leptin in the course of inflammation and severe sepsis. BMC Infect Dis. 2012;12:217.

13. Behnes M, Brueckmann M, Lang S, Putensen C, Saur J, Borggrefe M, Hoffmann U. Alterations of adiponectin in the course of inflammation and severe sepsis. Shock. 2012;38:243-8.

14. Vassiliadi DA, Tzanela M, Kotanidou A, Orfanos SE, Nikitas N, Armaganidis A, Koutsilieris M, Roussos C, Tsagarakis S, Dimopoulou I. Serial changes in adiponectin and resistin in critically ill patients with sepsis: associations with sepsis phase, severity, and circulating cytokine levels. J Crit Care. 2012;27:400-9.

15. Arnalich F, Lopez J, Codoceo R, Jimnez M, Madero R, Montiel C. Relationship of plasma leptin to plasma cytokines and human survivalin sepsis and septic shock. J Infect Dis. 1999;180:908-11.

16. Bracho-Riquelme RL, Reyes-Romero MA, Pescador N, Flores-Garcia Al. A leptin serum concentration less than $10 \mathrm{ng} / \mathrm{ml}$ is a predictive marker of outcome in patients with moderate to severe secondary peritonitis. Eur Surg Res. 2008:41:238-44.

17. Koch A, Sanson E, Voigt S, Helm A, Trautwein C, Tacke F. Serum adiponectin upon admission to the intensive care unit may predict mortality in critically ill patients. J Crit Care. 2011;26:166-74. 
18. Bornstein SR, Licinio J, Tauchnitz R, Engelmann L, Negrao AB, Gold P, Chrousos GP. Plasma leptin levels are increased in survivors of acute sepsis: associated loss of diurnal rhythm, in cortisol and leptin secretion. J Clin Endocrinol Metab. 1998;83:280-3.

19. Koch A, Weiskirchen R, Zimmermann HW, Sanson E, Trautwein C, Tacke F. Relevance of serum leptin and leptin-receptor concentrations in critically ill patients. Mediat Inflamm. 2010;2010

20. Papathanassoglou ED, Moynihan JA, Ackerman MH, Mantzoros CS. Serum leptin levels are higher but are not independently associated with severity or mortality in the multiple organ dysfunction/systemic inflammatory response syndrome: a matched case control and a longitudinal study. Clin Endocrinol. 2001;54:225-33.

21. Grigoras I, Branisteanu DD, Ungureanu D, Rusu D, Ristescu I. Early dynamics of leptin plasma level in surgical critically ill patients. A prospective comparative study. Chirurgia (Bucur). 2014;109:66-72.

22. Hillenbrand A, Xu P, Zhou S, Blatz A, Weiss M, Hafner S, Henne-Bruns D, Knippschild U. Circulating adipokine levels and prognostic value in septic patients. J Inflamm (Lond). 2016;13:30.

23. Norberg M, Wall S, Boman K, Weinehall L. The Vasterbotten intervention Programme: background, design and implications. Glob Health Action. 2010;3

24. Eriksson $M$, Holmgren $L$, Janlert $U$, Jansson JH, Lundblad D, Stegmayr $B$, Soderberg S, Eliasson M. Large improvements in major cardiovascular risk factors in the population of northern Sweden: the MONICA study 19862009. J Intern Med. 2011;269:219-31.

25. Bone RC, Balk RA, Cerra FB, Dellinger RP, Fein AM, Knaus WA, Schein RM, Sibbald WJ. Definitions for sepsis and organ failure and guidelines for the use of innovative therapies in sepsis. The ACCP/SCCM consensus conference committee. American College of Chest Physicians/Society of Critical Care Medicine. Chest. 1992;101:1644-55.

26. Knaus WA, Draper EA, Wagner DP, Zimmerman JE. APACHE II: a severity of disease classification system. Crit Care Med. 1985;13:818-29.

27. Vincent JL, Moreno R, Takala J, Willatts S, De Mendonca A, Bruining H, Reinhart CK, Suter PM, Thijs LG. The SOFA (sepsis-related organ failure assessment) score to describe organ dysfunction/failure. On behalf of the working group on sepsis-related problems of the European Society of Intensive Care Medicine. Intensive Care Med. 1996;22:707-10.

28. Definition and diagnosis of diabetes mellitus and intermediate hyperglycaemia. Report of a WHO/IDF consultation: World Health Organization; 2006.

29. Weinehall L, Hallgren CG, Westman G, Janlert U, Wall S. Reduction of selection bias in primary prevention of cardiovascular disease through involvement of primary health care. Scand J Prim Health Care. 1998;16:171-6.

30. Bracho-Riquelme RL, Loera-Castaneda V, Torres-Valenzuela A, LoeraCastaneda GA, Sanchez-Ramirez JP. Leptin and leptin receptor polymorphisms are associated with poor outcome (death) in patients with non-appendicular secondary peritonitis. Crit Care. 2011;15:R227.

31. Antuna-Puente B, Feve B, Fellahi S, Bastard JP. Adipokines: the missing link between insulin resistance and obesity. Diabetes Metab. 2008;34:2-11.

32. Marques MB, Langouche L. Endocrine, metabolic, and morphologic alterations of adipose tissue during critical illness. Crit Care Med. 2013:41:317-25.

33. Singer G, Granger DN. Inflammatory responses underlying the microvascular dysfunction associated with obesity and insulin resistance. Microcirculation. 2007;14:375-87.

34. Martin SS, Qasim A, Reilly MP. Leptin resistance: a possible interface of inflammation and metabolism in obesity-related cardiovascular disease. J Am Coll Cardiol. 2008;52:1201-10.

35. Ntaios G, Gatselis NK, Makaritsis K, Dalekos GN. Adipokines as mediators of endothelial function and atherosclerosis. Atherosclerosis. 2013;227:216-21

36. Shapiro NI, Schuetz P, Yano K, Sorasaki M, Parikh SM, Jones AE, Trzeciak S, Ngo L, Aird WC. The association of endothelial cell signaling, severity of illness, and organ dysfunction in sepsis. Crit Care. 2010;14:R182.

37. Shapiro NI, Khankin EV, Van Meurs M, Shih SC, Lu S, Yano M, Castro PR, Maratos-Flier E, Parikh SM, Karumanchi SA, Yano K. Leptin exacerbates sepsis-mediated morbidity and mortality. J Immunol. 2010;185:517-24.

38. Maruna P, Gurlich R, Frasko R, Haluzik M. Serum leptin levels in septic men correlate well with C-reactive protein (CRP) and TNF-alpha but not with BMI. Physiol Res. 2001;50:589-94.

39. Blanco-Quiros A, Casado-Flores J, Arranz E, Garrote JA, Asensio J, Perez A. Influence of leptin levels and body weight in survival of children with sepsis. Acta Paediatr. 2002;91:626-31.
40. Chen K, Li F, Li J, Cai H, Strom S, Bisello A, Kelley DE, Friedman-Einat M, Skibinski GA, McCrory MA, et al. Induction of leptin resistance through direct interaction of C-reactive protein with leptin. Nat Med. 2006;12:425-32.

41. Clegg DJ, Riedy CA, Smith KA, Benoit SC, Woods SC. Differential sensitivity to central leptin and insulin in male and female rats. Diabetes. 2003;52:682-7.

42. Meli R, Pacilio M, Raso GM, Esposito E, Coppola A, Nasti A, Di Carlo C, Nappi C, Di Carlo R. Estrogen and raloxifene modulate leptin and its receptor in hypothalamus and adipose tissue from ovariectomized rats. Endocrinology. 2004;145:3115-21.

43. Lilja M, Rolandsson O, Norberg M, Soderberg S. The impact of leptin and adiponectin on incident type 2 diabetes is modified by sex and insulin resistance. Metab Syndr Relat Disord. 2012;10:143-51.

44. Soderberg S, Stegmayr B, Stenlund H, Sjostrom LG, Agren A, Johansson L, Weinehall L, Olsson T. Leptin, but not adiponectin, predicts stroke in males. $J$ Intern Med. 2004;256:128-36

45. Mayr FB, Yende S, Angus DC. Epidemiology of severe sepsis. Virulence. 2014:5:4-11.

46. Turan A, Mascha EJ, Roberman D, Turner PL, You J, Kurz A, Sessler DI, Saager L. Smoking and perioperative outcomes. Anesthesiology. 2011;114:837-46.

47. Nicklas BJ, Tomoyasu N, Muir J, Goldberg AP. Effects of cigarette smoking and its cessation on body weight and plasma leptin levels. Metabolism. 1999:48:804-8.

48. Lilja M, Rolandsson O, Shaw JE, Pauvaday V, Cameron AJ, Tuomilehto J, Alberti KG, Zimmet PZ, Soderberg S. Higher leptin levels in Asian Indians than creoles and Europids: a potential explanation for increased metabolic risk. Int J Obes. 2010;34:878-85.

49. Ma Z, Gingerich RL, Santiago JV, Klein S, Smith CH, Landt M. Radioimmunoassay of leptin in human plasma. Clin Chem. 1996;42:942-6.

\section{Submit your next manuscript to BioMed Central and we will help you at every step:}

- We accept pre-submission inquiries

- Our selector tool helps you to find the most relevant journal

- We provide round the clock customer support

- Convenient online submission

- Thorough peer review

- Inclusion in PubMed and all major indexing services

- Maximum visibility for your research

Submit your manuscript at www.biomedcentral.com/submit
) Biomed Central 